\title{
A Brief Analysis of China's Economic Situation and Trend Forecast
}

\author{
Yang Yanan \\ International Business School, Shaanxi Normal University \\ Xi'an, Shaanxi 710119 \\ 342661012@qq.com
}

\begin{abstract}
This paper analyzes the current situation of China's economy through some data of China's economy. By means of kuznets inverse $U$ curve theory, we learned that China is in the second stage of the curve according to the two kuznets curves of income distribution and environment. On the basis of the trend prediction about the status quo of China's economy, we have drew the following conclusion: as the foundation of the economy in our country, the position of agriculture over a period of time in the future remains the same, but with the development of industrial process industrial structure showing the tendency of heavy industrialization, which is a universal rule in the process of industrialization in many countries; at the same time, the information industry will become the leading industry of our country in the future; the tertiary industry represented by service industry will develop rapidly.
\end{abstract}

Keywords-Economic situation; Trend forecast; China; Kuznets

\section{INTRODUCTION}

China's economic development has entered a new era, facing new problems and contradictions. In order to achieve the new target of the new era, we can't simply pursue the economic growth, but more pay attention to quality and economic benefits of economic growth.

After China entered the upper middle income country in 2010 , its economic growth began to slow down. The economic growth rate has slowed from an average annual rate of more than $10 \%$ in the past three decades to $6.7 \%$ in 2016 . Future economic growth continuing to slow is inevitable, but depends on the range and degree of slowdown by deepening reform and opening up and encouraging innovation measures.

\section{AN OVERVIEW OF CHINA'S ECONOMIC SITUATION}

\section{A. Summary of the total}

We can see from the figure 1-1 that China's economic development has been very stable in the past decade [1]

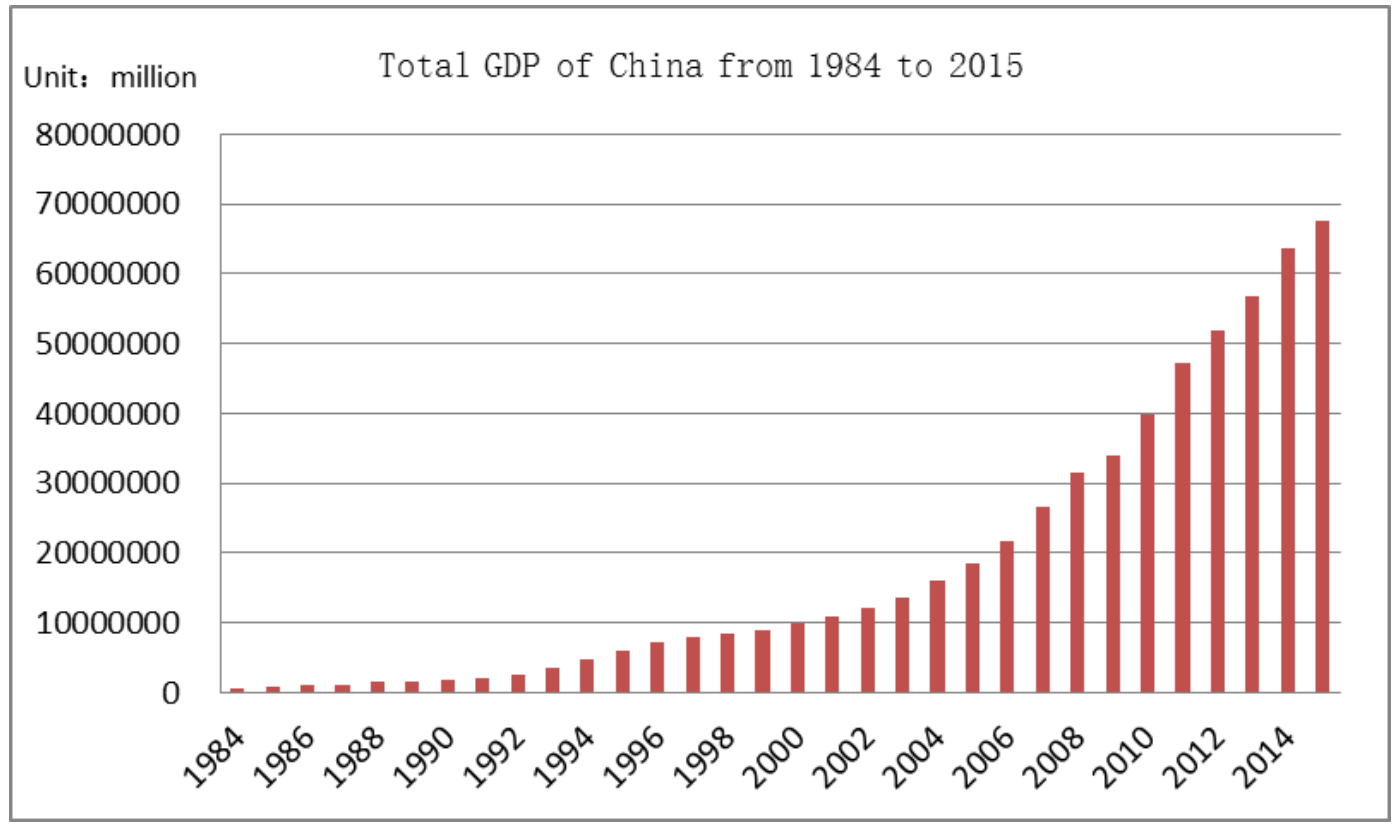

Fig. 1 Total GDP of China from 1984 to 2015

This is a decade of rapid growth of China's national strength: as can be seen from figure 1-1, GDP has increased nearly sixfold in the past ten years, from over 10 trillion yuan in 2002 to over 67 trillion yuan in 2015 , becoming the second 
largest economy in the world. In 2002, China's gross domestic product (GDP) has just reached 10 trillion yuan, in 2011, that figure has more than 47 trillion yuan, according to the release of economic data in 2010 at the beginning of 2011, China's gross domestic product (GDP) for $\$ 5.8786$ trillion, more than $\$ 5.4742$ trillion in Japan, as the world's second largest economy.

This is a decade of rapid economic development in China: figure 1-2 clearly shows the view that the annual GDP growth rate is $10 \%$, while the annual global GDP growth rate is only $3.9 \%$ in the same period. Since 2003, China's economy has entered a cycle of high growth, with GDP growth reaching a peak of $14.2 \%$ in 2007.In 2008 the global financial crisis, to protect the international financial crisis, China's determination to implement the stimulus package expanding domestic demand, sustaining economic growth, economic growth in the global first to realize the beautiful "V" shape inversion, to return to double-digit growth, China's GDP growth of $10.4 \%$ in 2010.Since the second half of 2011, influenced by the European sovereign debt crisis spread, China's economic growth eased back[2], especially since 2015, the domestic enterprise profit growth decline, shrinking foreign trade, insufficient credit demand, economic development and new challenges. In this context, the central government has made timely pre-adjustments and fine-tuning and deployed a series of policies and measures to stabilize growth, such as lowering the reserve requirement and lowering interest rates.

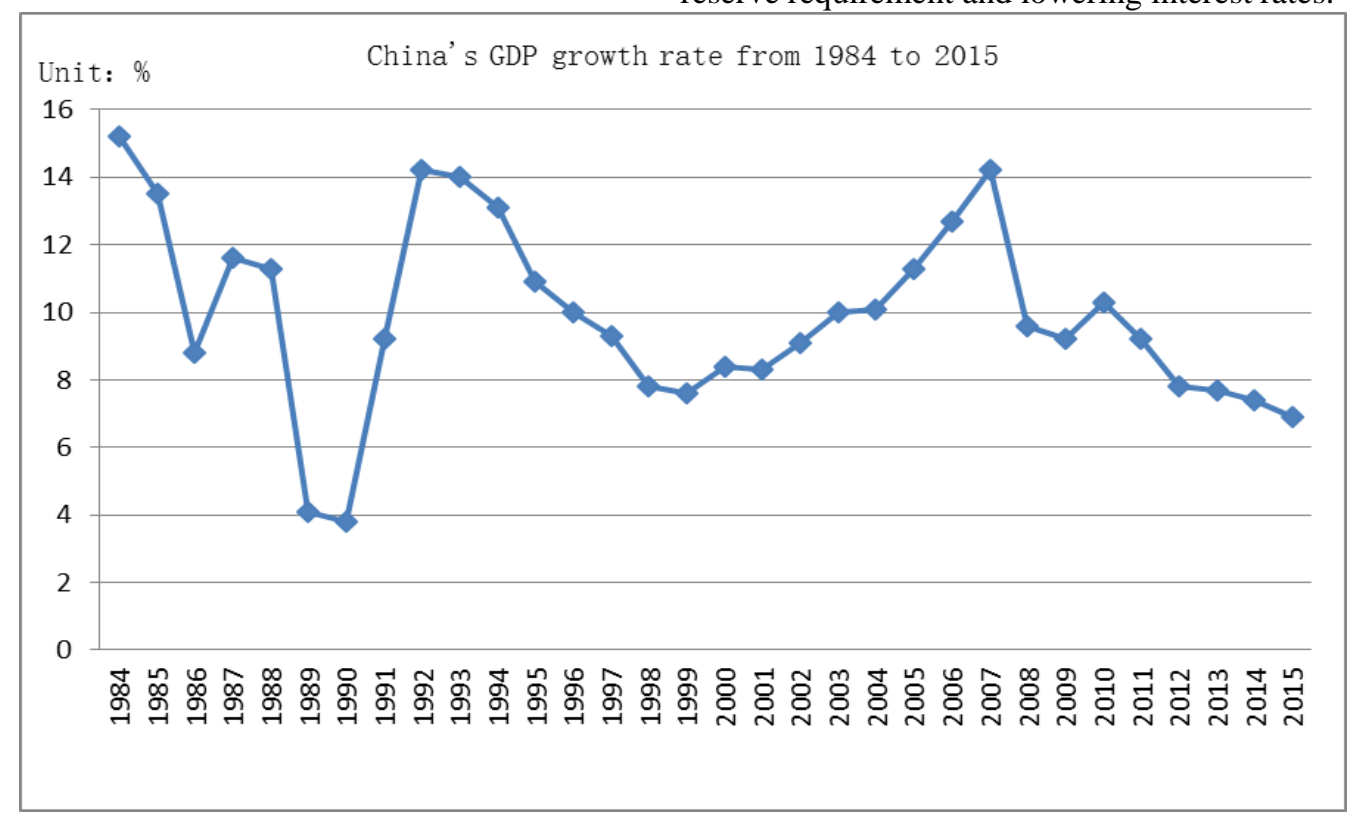

Fig. 2 China's GDP growth rates from 1984 to 2015

However, along with economic growth, there is also a new normal of the economy. From 2010 to 2015, the GDP growth rate dropped all the way down, and in 2015 , it fell below the $7 \%$ threshold. The enterprise benefit declines, the real estate industry shows a weak situation, and the investment shrinks [3].

At present, the world economy continues to recover and the outlook for economic growth has improved, but the unstable and uncertain factors of the recovery remain prominent. China still faces a complex environment at home and abroad. On the one hand, some western powers, such as the United States, have put forward the theory of China threat. While supporting China, they are always alert to China. On the other hand, when four Asian tigers have lost their development potential, the surrounding environment is good for our country, the Chinese government has always been enlightened policy welcoming the surrounding countries to "free rider", sharing common prosperity and bonus share reform. This is a very good development environment for our country to develop in the future to lay a good economic foundation.

\section{B. Current industrial structure}

Since the reform and opening up, the industrial structure of our country has experienced great changes. From the perspective of long-term changing trend, the ratio relationship between the three secondary industries has improved significantly, and the industrial structure is changing towards rationalization. 


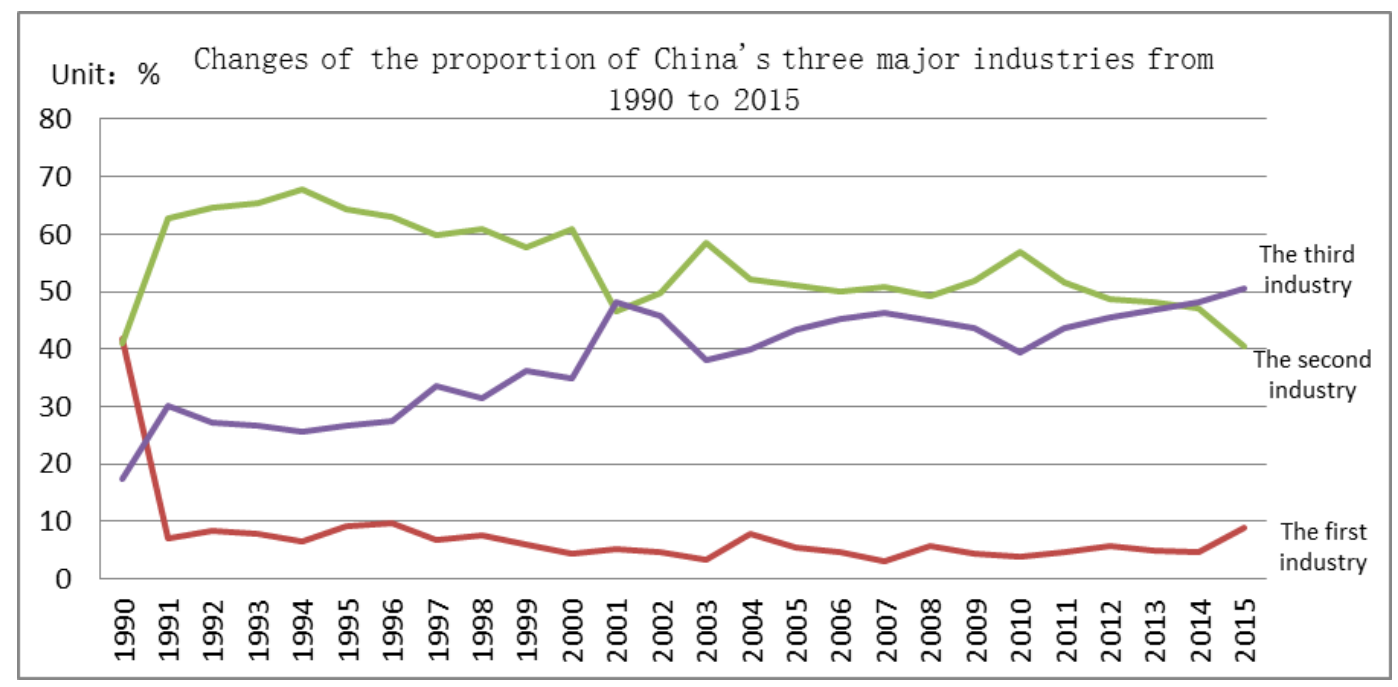

Fig. 3 Changes of the proportion of China's three major industries

The proportion of primary industry is declining. At the beginning of the reform and opening up period, the proportion of primary industry in China's GDP was about 3\%. However, by the third quarter of 2007, it had fallen to $10.97 \%$, a significant decline. As can be seen from figure 1-3, from 1991 to 2015 , the primary industry maintained a stable level of less than $10 \%$.

The proportion of secondary industry in GDP showed a trend of decreasing first and then rising later, but in general, there was no significant change. In the GDP structure, the proportion of the secondary industry dropped from $48.22 \%$ in 1980 to $41.34 \%$ in 1990 . In 2007 , it rose again to $50.27 \%$.

The proportion of tertiary industry in GDP is on the rise. Since the reform and opening up to the early $1980 \mathrm{~s}$, the third industry in the GDP structure proportion has not changed, but after 1983, the proportion of the tertiary industry rapidly rising, in 1985 more than the first industry. In 2002, the third industry and the gap between the second industry the most small and are only $3.07 \%$, but since 2002 , the proportion of the tertiary industry in GDP structure began to present the rising trend, between 2014 and 2015, more than the second industry and the GDP structure first, become the largest industry in contribution to GDP. This indicates that China's tertiary industry has started a strong growth momentum [4].

Since entering the 21st century, China's industrial structure has been continuously optimized. First industry growth is relatively slow, the second industry rapid growth, the third industry breakthrough in trade and business, food is given priority to the single development pattern, speeding up the financial, insurance, the development of the research and development, consulting and other industries. At the same time, the proportion of employment in the primary industry has dropped significantly, the proportion of employment in the secondary industry has grown slowly, and the proportion of employment in the tertiary industry has grown faster than that in the secondary industry. Generally speaking, China's industrial structure is constantly optimized on the basis of maintaining two, three and one types. However, no matter from static or dynamic perspective to analyze China's current industrial structure, many problems still exist. For example, by the end of 2007, the output value of China's three secondary industrial structures was 2891 billion yuan, accounting for $11.7 \%$ of GDP. The added value of secondary industry is 12138.1 billion yuan, accounting for $49.2 \%$ of GDP. The added value of tertiary industry is 9632.8 billion yuan, accounting for $39.1 \%$ of GDP. It shows that China's national economy also relies too much on agriculture, and the service industry is rather backward. Although China's tertiary industry accounted for more than the secondary industry at the end of 2015, this is not unrelated to the decline of the secondary industry. In the composition of GDP of developed countries, the proportion of primary industry is generally no more than $5 \%$, the proportion of secondary industry is generally no more than $30 \%$, and the proportion of tertiary industry is the largest, generally over 65\%.Compared with developed countries, China's industrial structure still has room for optimization.

\section{ANALYSIS OF KUZNETS' GRAPH ON THE CURRENT STATE OF THE ECONOMY}

Kuznets curve shows that at the beginning of the economic development process, especially in the national per capita income rose from the lowest to moderate levels, income distribution situation to deteriorate, which in turn with the economic development, gradually improve, finally achieve fair income distribution, the inverted $U$ shape. The vertical axis is the gini coefficient, and the horizontal axis is the income status. 


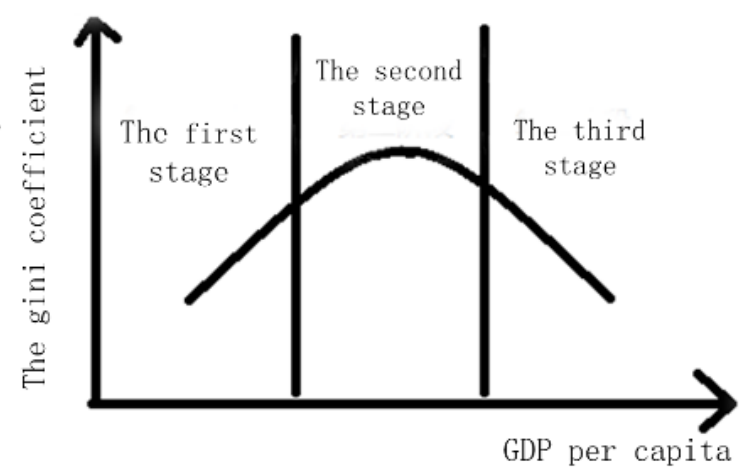

Fig. 4 Kuznets curve of income distribution

Kuznets curve shows that at the beginning of the economic development process, especially in the national per capita income rose from the lowest to moderate levels, income distribution situation to deteriorate, which in turn with the economic development, gradually improve, finally achieve fair income distribution, the inverted $U$ shape. The vertical axis is the gini coefficient, and the horizontal axis is the income status.

China's per capita GDP in 2014 was about $\$ 7485$, still lagging behind many countries. China's per capita GDP is still around 90 in the world, ranking medium among more than 200 countries and regions. However, China's gini coefficient, according to the folk statistics in recent years, is basically greater than 0.5 , above the so-called great gap between the rich and the poor. According to the kuznets curve theory (FIG. 2-1), China is now in the second stage of the curve, namely the socalled middle income trap [5]. According to the trend of figure $2-2$, it also fits exactly such an interval.

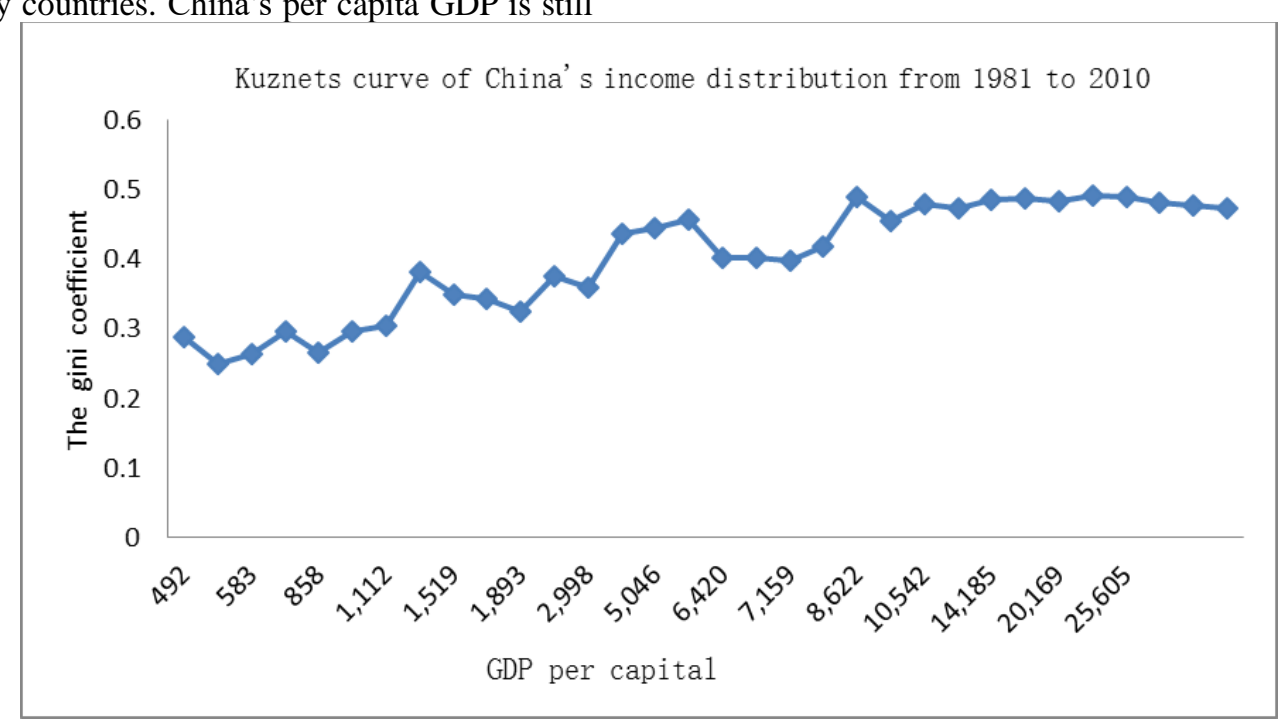

Fig. 5 Kuznets curve of China's income distribution from 1981 to 2010

In 1991, American environmentalists Grossman and Krueger will kuznets curve for the first time introduced into the study of the relationship between economic growth and environmental pollution, it is assumed that the pollution level of a country will be increased with the increase of economic development and national income levels increase, when economic development to a certain extent, the pollution level with the rise and fall of national income. If expressed in longitudinal axis pollution levels (emissions, etc.), the horizontal axis shows economic growth (GDP per capita, etc.), pollution levels can be obtained between economic growth and scatter Curve shows "inverted U", namely the Environmental Kuznets Curve (Environmental Kuznets Curve) [6].

As China's extensive manufacturing expansion reaches its limits, China's position as the world's factory has been established. However, at a time when China's per capita GDP reached a moderately developed level of 5,000 us dollars, China also entered the peak of environmental pressure.

In terms of the area of environmental pollution, it has spread rapidly from the economically developed eastern and southern regions to the central and western regions and the northern regions to the whole country. In the last three or four 
years, the central and western regions have intensified their development efforts, and low-end industries have shifted to the central and western regions. The once crystal clear streams become gutter, which is no longer an isolated phenomenon in the developed areas of the east. From the perspective of the spatial distribution of environmental pollution, from the sky to the sea, from land to rivers, from the surface to the ground, whether it is air, water or soil, it is widely and seriously polluted.

And the same time, the pollution is in a high level. China's per capita water resources only account for $1 / 4$ of the world average level, water resources are scarce. One-third of the total water resources of China is groundwater, however, it's reported for continuous monitoring data of 118 cities, according to about $64 \%$ of the city suffered serious pollution of groundwater,33\% by light pollution of groundwater, basic cleaning to only $3 \%$ of groundwater.

At present, more than $10 \%$ of the cultivated land area in China has been polluted by heavy metal, totaling about 150 million mu. In addition, there are 32.5 million mu of farmland polluted by sewage irrigation. About 2 million mu of land is occupied and destroyed by solid waste storage, most of which is concentrated in economically developed areas. As a result, China has "12 million tons of grain contaminated by heavy metals every year, resulting in more than 20 billion yuan of direct economic losses.

According to the Asian development bank and tsinghua university's latest report, "analysis of the law of the People's Republic of China national environmental 500 large cities in China, less than $1 \%$ to the world health organization (who) air quality standards.

Pollution disasters caused by industrial development are not uncommon in history. However, China's current environmental pollution problem is comparable to the worst in history. For example, the notorious London smog is on the same level as Beijing's smog today. It is recorded that more than 4,000 people died in London in December 1952 during four days of heavy fog, and more than 8,000 died two months later. Doctors' memoirs show that hospitals were too crowded to be treated. In 2012 , more than 8,500 people died prematurely in four cities -Beijing, Shanghai, Guangzhou and Xi'an -- as a result of multiple diseases caused by PM2.5, according to a study.

In conclusion, China's environmental pollution has reached an extreme level. According to the kuznets curve theory, China is now in the second stage of the curve.

\section{TREND FORECAST AND FUTURE OUTLOOK}

The overall judgment of the three industrial structure changes is that the intermediate stage of China's industrialization process may last beyond 2020.In one, two, three industries, while the second industry presents the weakness, beyond the streak, the tertiary industry, but on the whole, the pattern of China's economy is given priority to with the second industry is unlikely to happen in 2020 years ago a thorough transformation. The state now advocates structural adjustment, and when it comes to complete adjustment, it should also be around 2020.From the 13th five-year plan to 2020 , the proportion of primary industry income will continue to decline. The proportion of tertiary industry may increase significantly during the 13th five-year plan period. During the 13th five-year plan period, the proportion of secondary industry was basically stable or even decreased.

\section{A. The unchanged foundation position of agricultural}

The proportion of agriculture in the national economy will continue to decline, but its importance and basic status will not change. In traditional agriculture, the proportion of planting industry will decrease, and the contribution of fishery and animal husbandry will increase. Within the planting industry, the proportion of food crops will slowly decline, and the proportion of cash crops, vegetable crops and other crops will increase.

\section{B. Industrial restructuring}

China is one of the largest IT product consuming countries in the world, and IT is also the country that participates in the international division of labor in the information industry manufacturing industry in the world. China's eastern coastal areas has focused a great deal of necessary human capital development of information industry, at the same time, the low labor cost is the IT industry in China manufacturing industry with strong international competitiveness. By participating in the international division of labor in manufacturing of IT industry in our country, can not only realize full employment, also can obtain higher comparative advantage, through continuous "dry middle school" and "high school", will be gradually accumulated strong ability of technology development of IT industry. Information industry should and can become the leading industry of China in the future [7].

\section{Rapid development of the service industry}

With the advance of industrialization, China will enter a period of rapid urbanization. The development of cities will lead to the growth of investment in the tertiary sector, especially in real estate and urban infrastructure. There will be an increasing demand for services; the demand of socialization of production on producer services will also expand. At the same time, with the improvement of living standards, the reform in housing, health care, education and other aspects will continue to affect people's expectations and consumption expenditure, and the proportion of service consumption expenditure will continue to increase. All these factors will drive the rapid development of the service industry. Improve people's life levels of culture, education, tourism, telecommunications, provide efficient service for the production of finance, insurance, professional consulting and services will continue to get rapid development, e-commerce, logistics, will get rapid development, new pattern of our country's economy will gradually from the industrial economy primarily to give priority to in order to service economy. 


\section{CONCLUSION}

\section{A. Urbanization}

From the end of last century to the beginning of the $21 \mathrm{st}$ century, China's urbanization has experienced more than 30 years of development and has initially formed a certain scale. Urbanization process, however, when it is truly in full swing in recent years, urban village transformation, rural urbanization is obviously can feel the change in recent years, the national bureau of statistics released in 2014 China's urbanization rate reached $54.77 \%$.The Chinese government also proposed a new urbanization plan in 2014. Therefore, in the next 10-20 years, urbanization can drive the development of the real estate industry and the development of the tertiary industry. At the very least, this will not lead to a sharp contraction in China's economy, but there is still much room for development.

\section{B. The development of the tertiary industry}

There is no doubt that the development of urbanization will inevitably lead to the development of the service industry. During the urbanization, the tertiary industry should seize the opportunity and forge ahead vigorously.

\section{Intensive agricultural modernization}

Land use after urbanization is greatly convenient. Land can be concentrated, modernized and intensive production can be carried out, agricultural modernization can be realized, and urbanization can be closely followed.

\section{Population aging}

While developing, there are also problems that need to be faced. The aging of population is a very real and serious problem in the future. It is estimated that the number of elderly people over 60 will reach 216 million in 2015, accounting for $16.7 \%$ of the total population. The number of elderly people over 80 will reach 24 million, accounting for $11.1 \%$ of the elderly population. More than 51 million people over 65 will live in empty nests, accounting for nearly a quarter of the elderly population.

Overall, the acceleration of population aging in our country development, and industrialization, urbanization and modernization, accompanying with the phase difference, regional difference, income difference between urban and rural areas to expand overlap, and economic transition and social transformation and cultural transformation, increased new difficulty to deal with an ageing population work, also provides the new conditions.

\section{E. Labor structure and employment}

As pointed out in the blue book of human resources, China's labor market is mainly faced with two problems. On the other hand, the labor market protection inequality, the informal employment phenomenon is still serious. Therefore, from the perspective of optimizing employment environment, improve people's livelihood, in the future should focus on and solve the problem are: first, focus on university students' employment difficult, build a long-standing mechanism to promote the university students' employment; Second, pay more attention to people's livelihood and build a flexible and secure labor market. Third, we will improve the labor market system and strengthen basic protection for workers.

\section{REFERENCES}

[1] Zhang shiquan, sun lanlan. Reflections on the current situation, characteristics and prospects of China's economy $[\mathrm{J}]$. International technical and economic research, 1999, (1): 23-28. In Chinese

[2] Shimron maruyama. Current situation and future trend of China's economy [J]. Energy base construction, 1998, (1): 40-41. In Chinese

[3] Gu haidong. Research on China's economic situation and trend [J]. Mass technology, 2006, (8): 176-177. In Chinese

[4] Chen lili, tao xiaojuan, ye dongxiu. On the problems, characteristics and evolution directions of China's current industrial structure [J]. Mass commerce, 2010, (10): 58. In Chinese

[5] Du bingjie. "The middle-income trap" and China's current situation [J]. Journal of qiqihar university (philosophy and social science edition), 2016, (1): 46-50. In Chinese

[6] Yu yina, Chen lili. Research progress of China's environmental kuznets curve [J]. Journal of ecological environment, 2012, (12): 2018-2023. In Chinese

[7] Yue quanhua. Optimization and upgrading of China's industrial structure and relevant industrial policy recommendations $[\mathrm{J}]$. Social scientist, 2009, (3): 62-66. In Chinese 